\title{
INFLUÊNCIA DO BOCAL DE ENTRADA DE AR NA FLUIDODINÂMICA E SECAGEM DE PASTAS EM LEITO DE JORRO
}

\author{
M. T. B. PERAZZINI, F. B. FREIRE, J. T. FREIRE* \\ Universidade Federal de São Carlos, Departamento de Engenharia Química \\ *e-mail: freire@ufscar.br
}

\begin{abstract}
RESUMO
Neste trabalho foi investigada a influência do bocal de entrada de ar na fluidodinâmica e secagem de pastas em leito de jorro. O equipamento utilizado era composto por uma coluna cilíndrica de $120 \mathrm{~cm}$ de altura e $30 \mathrm{~cm}$ de diâmetro, uma base cônica com ângulo de $45^{\circ}$, altura de $28,70 \mathrm{~cm}$ e diâmetro de entrada de $3 \mathrm{~cm}$ e duas geometrias distintas de bocal de entrada de ar (tubo reto e Venturi). Como material inerte utilizou-se partículas de polietileno com 4,38 mm de diâmetro e massa específica de $930,5 \pm 0,3 \mathrm{~kg} / \mathrm{m}^{3}$. Como pasta selecionou-se o leite desnatado devido este, apresentar alterações significativas na movimentação das partículas, conforme estudos já realizados pelo Centro de Secagem do DEQ/UFSCar. Os ensaios de secagem foram conduzidos a $100^{\circ} \mathrm{C}$ e $1,30 u_{m j}$. Os resultados obtidos mostraram que o bocal de entrada de ar exerceu efeito tanto na fluidodinâmica do leito quanto na secagem do leite desnatado em leito de jorro, uma vez que, a maior estabilidade do leito e a maior capacidade de secagem foram obtidas quando utilizado o bocal do tipo Venturi. Estes resultados evidenciam que o processo de secagem em leito de jorro é complexo e além das características da pasta, as demais variáveis de processo também devem ser levadas em consideração.
\end{abstract}

\section{INTRODUÇÃO}

Desde a sua descoberta em 1954, o leito de jorro tem sido amplamente estudado. No entanto, a sua aplicação em escala industrial para a secagem de pastas ainda apresenta algumas restrições, como dificuldade de ampliação de escala e, sobretudo por não ser possível prever ainda a capacidade de secagem do leito para um determinado tipo de pasta. Isto porque, as características do material a ser seco exercem forte efeito no desempenho do processo. Uma melhor análise sobre este assunto pode ser encontrada nos trabalhos de Pham (1983), Medeiros (2001), Almeida (2009) e Nascimento (2013).

A complexidade dos fenômenos de transferência de calor e massa envolvidos no processo de secagem de pastas em leito de jorro pode não ser apenas devido às características da pasta, mas também das diferentes variáveis de operação envolvidas no processo, como por exemplo, as características geométricas do leito.

Olazar et al. (1992) estudaram o efeito da geometria do bocal de entrada de ar na estabilidade do leito de jorro. Os autores estabeleceram que os limites máximos e mínimos para a razão entre o diâmetro do bocal de entrada de ar $\left(\mathrm{D}_{0}\right)$ e o diâmetro de entrada da base cônica inferior $\left(\mathrm{D}_{\mathrm{i}}\right)$ devem estar entre 0,50 e 0,83 . O limite inferior foi estabelecido devido à queda de pressão e a constatação de zonas mortas no leito, o que é um problema agravante quando se trabalha com circulação de sólidos. Já para valores de $\left(\mathrm{D}_{0} / \mathrm{D}_{\mathrm{i}}\right)$ acima do recomendado pelos autores verificou-se um regime de jorro instável. 
Estes autores observaram ainda que, existe um limite máximo e mínimo de ângulo de cone para cada configuração de leito existente. Para um leito de jorro cônico o limite inferior é de $28^{\circ}$ e o superior não possui restrições. No caso de um leito na configuração jet, os ângulos de cone devem estar entre 28 e $45^{\circ}$. Foi verificado que ângulos de cone inferiores a $28^{\circ}$ não proporcionaram ao leito o movimento cíclico dos sólidos, característico do regime de jorro. Entretanto, para ângulos maiores que $45^{\circ}$ verificou-se uma instabilidade, devido a um fenômeno de rotação na circulação do gás.

De acordo com Olazar San José e Bilbao (2011), ângulos de cone maiores que $60^{\circ}$ não são recomendados, visto que apresentam baixa taxa de circulação de inertes, principalmente para leitos com grandes quantidades de partículas. Passos et al. (1997) também observaram que ângulos de cone inferiores a $60^{\circ}$ melhoram a aeração na região anular e a capacidade de secagem do leito de jorro. Já Elperin et al. (1967) citado por Mathur e Epstein (1974) verificaram que para leitos cônicos, os ângulos de cone entre $40-45^{\circ}$ maximizaram a taxa de circulação de sólidos.

Com base no contexto apresentado, é clara a necessidade de se obter informações mais precisas sobre a secagem de pastas em leito de jorro, visto que grande parte dos trabalhos fornecidos pela literatura avalia 0 efeito das características geométricas do leito apenas para a fluidodinâmica do leito de jorro sem a presença de pasta. Desta forma, o objetivo do presente trabalho foi estudar a secagem de uma pasta, leite desnatado, empregando configurações distintas de bocal de entrada de ar a fim de verificar o efeito deste elemento na capacidade de secagem e estabilidade do leito. Com base na literatura apresentada, optou-se por trabalhar com um leito de jorro cônico e ângulo de cone de $45^{\circ}$.

\section{MATERIAIS E MÉTODOS}

O leito de jorro utilizado neste trabalho é composto por uma coluna cilíndrica de aço inox, $120 \mathrm{~cm}$ de altura, $30 \mathrm{~cm}$ de diâmetro, base cônica com ângulo de $45^{\circ}, 23,70 \mathrm{~cm}$ de altura e diâmetro de entrada de $3 \mathrm{~cm}$.

A unidade experimental era constituída ainda por um soprador (1); válvulas gaveta (2); medidor de vazão tipo Venturi (3); trocador de calor (4); controlador de temperatura (5); câmara de secagem (6); compressor de ar (7); bomba peristáltica (8); reservatório de pasta (9); bocal de entrada de ar (10) e um sistema de aquisição de dados (11). A Figura 1 apresenta a unidade experimental utilizada neste trabalho.

Figura 1 - Esquema da unidade experimental.

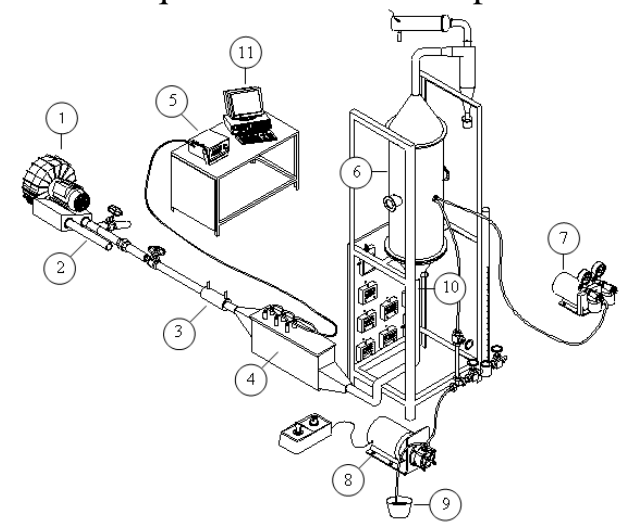

\subsection{Bocal de Entrada de Ar}

Duas configurações distintas de bocal de entrada de ar foram estudadas, o bocal tipo Venturi e o bocal do tipo tubo reto. A Figura 2 apresenta os bocais de entrada de ar estudados e suas respectivas dimensões.

Conforme mostra a Figura 2a, o bocal do tipo Venturi possui uma contração e expansão gradual da seção de escoamento, onde a expansão da área de saída do bocal funciona como um difusor de ar na base do leito. Este tipo de bocal tem sido amplamente utilizado nas pesquisas realizadas pelo Centro de Secagem do DEQ/UFSCar. Já, o segundo bocal (Figura 2b) é basicamente um tubo reto, cujas dimensões foram determinadas com 
base no trabalho de Olazar et al. (1992), em que os autores afirmam que os valores para a relação entre o diâmetro de entrada da base cônica e o diâmetro de entrada do bocal de entrada de ar $\left(\mathrm{D}_{\mathrm{i}} / \mathrm{D}_{0)}\right.$ deve estar entre 0,50 e 0,83 . O valor para esta razão utilizado nesta pesquisa foi correspondente a 0,60 .

Figura 2 - Bocal de entrada de ar: (a) Venturi e (b) tubo reto.
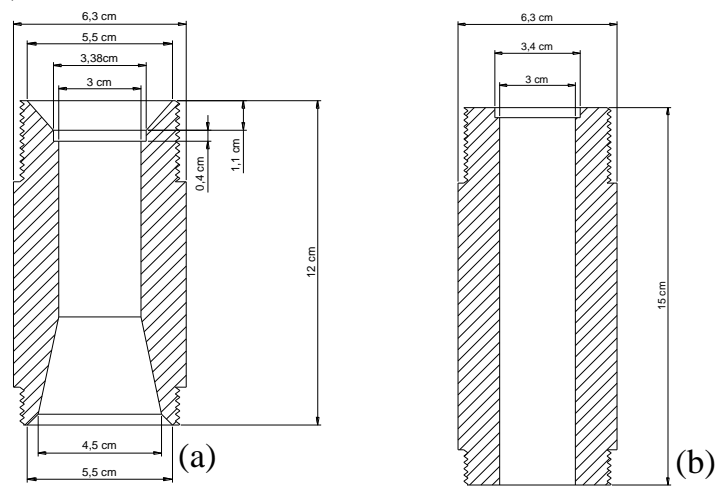

\subsection{Partículas Inertes e Pasta}

O procedimento experimental foi realizado empregando-se partículas de polietileno com 4,38 $\mathrm{mm}$ de diâmetro e massa específica de 930,5 $\pm 0,3 \mathrm{~kg} / \mathrm{m}^{3}$. Leite desnatado foi selecionado como pasta, devido este apresentar alterações significativas na movimentação das partículas e elevados valores do adimensional da queda de pressão, conforme relatado por Nascimento (2013). Altos valores da queda de pressão não são interessantes para o processo, uma vez que, representam um alto custo energético.

\subsection{Procedimento Experimental}

Os ensaios experimentais foram conduzidos utilizando um leito de jorro cônico, no qual três valores de massa de material inerte foram utilizados 1,50; 3,00 e $4,50 \mathrm{~kg}$, sendo suas respectivas alturas 18,24 e $28,70 \mathrm{~cm}$. Os ensaios de secagem foram conduzidos a $100^{\circ} \mathrm{C}$ e com velocidade do ar de entrada $30 \%$ acima da velocidade mínima de jorro.
Inicialmente, realizou-se a caracterização fluidodinâmica da unidade experimental, conforme a metodologia proposta em Mathur e Epstein (1974). Os ensaios fluidodinâmicos permitiram a obtenção dos valores de queda de pressão e velocidade do ar na condição de mínimo jorro. Posteriormente, foram conduzidos os testes de secagem do leite desnatado, a fim de determinar a capacidade máxima de secagem do leito e avaliar o efeito da geometria do bocal de entrada de ar na estabilidade do processo.

Durante todo o procedimento experimental foram monitorados e determinados os valores de velocidade do ar de entrada, da queda de pressão do leito, da temperatura do ar de entrada, do ar de saída, de bulbo seco e bulbo úmido na saída do ciclone. A coleta dos dados foi conduzida automaticamente em um intervalo de 30 segundos pelo sistema de aquisição de dados. A rotina labVIEW utilizada fornecia a média e o desvio padrão dos dados coletados.

\section{RESULTADOS E DISCUSSÕES}

\subsection{Fluidodinâmica do Leito de Jorro}

\subsubsection{Bocal Venturi}

Primeiramente, foram avaliados os dados fluidodinâmicos do leito de jorro vazio, sem a presença de partículas inertes "teste em branco". As equações obtidas a partir do ajuste dos dados experimentais são apresentadas na Tabela 1.

Tabela 1 - Dados obtidos nos testes em branco do leito de jorro a $100^{\circ} \mathrm{C}$ e ângulo de cone de $45^{\circ}$.

\begin{tabular}{cccc}
\hline Bocal & Função Potência & $\mathrm{R}^{2}$ & Eq. \\
\hline Venturi & $\Delta \mathrm{P}=3,07 \mathrm{u}^{1,87}$ & 0,9996 & $(1)$ \\
Tubo reto & $\Delta \mathrm{P}=4,02 \mathrm{u}^{1,81}$ & 0,9993 & $(2)$ \\
\hline
\end{tabular}

Os dados apresentados na Tabela 1 mostraram que a função utilizada apresentou bom ajuste aos dados experimentais, visto que 
os coeficientes de determinação, $\mathrm{R}^{2}$, para ambas as condições operacionais foram próximos a unidade. Os resultados mostram ainda, que os valores dos coeficientes de ajuste para ambos os bocais de entrada de ar foram distintos. Isto sugere uma interferência da geometria do bocal de entrada de ar no comportamento fluidodinâmico do leito de jorro.

Referindo-se aos ensaios fluidodinâmicos para o leito preenchido com partículas inertes, a Figura 3 apresenta a caracterização fluidodinâmica em triplicata nas condições de $4,50 \mathrm{~kg}$ de partículas de polietileno, $100^{\circ} \mathrm{C}$ e bocais de entrada de ar do tipo Venturi e tubo reto.

Figura 3 - Queda de pressão no leito de jorro em função da velocidade do ar de entrada.

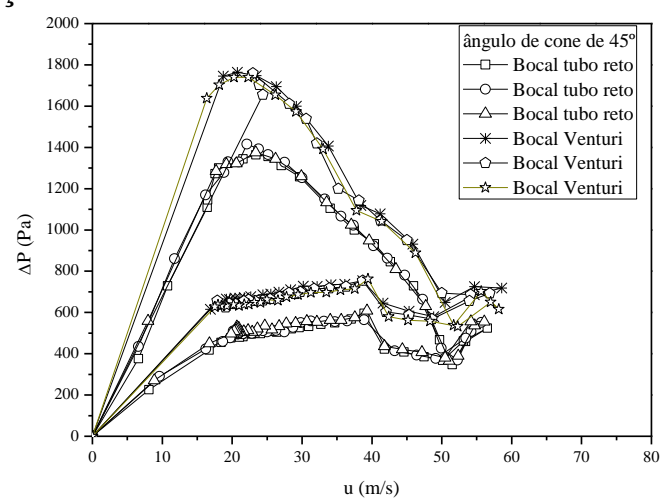

Como base nos dados apresentados na Figura 3, constatou-se que as curvas obtidas apresentaram um comportamento típico de leito de jorro, conforme resultados apresentados em Mathur e Epstein (1974). Estes resultados mostraram ainda uma histerese expressiva entre os dados de vazão de ar ascendente e descendente. Isso ocorre porque a força necessária para o rompimento do leito de partículas e formação do jorro é muito maior do que a força utilizada para manter o leito na condição de mínimo jorro. Desta forma, a queda de pressão máxima do leito é muito maior do que a queda de pressão de jorro mínimo.
Os demais dados fluidodinâmicos também foram obtidos em triplicata, o que permitiu a constatação da reprodutibilidade dos dados experimentais, bem como a determinação dos valores médios de velocidade mínima de jorro, $u_{m j}$, queda de pressão máxima do leito, $\Delta P_{\text {máx }}$, e queda de pressão de jorro mínimo, $\Delta P_{m j}$.

A Figura 4 apresenta os valores médios da velocidade mínima de jorro em função da massa de material inerte para o bocal do tipo Venturi e temperatura do ar de entrada de $100^{\circ} \mathrm{C}$.

Figura 4 - Valores médios de velocidade mínima de jorro em função da massa de material inerte.

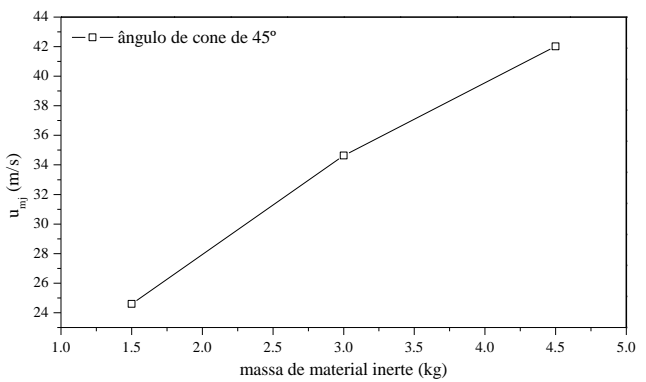

Os resultados apresentados na Figura 4 mostraram uma elevação praticamente linear dos valores de velocidade mínima de jorro com o aumento da massa de material inerte, $m_{p}$. Isto porque, um aumento de $m_{p}$ elevou a altura de leito estático utilizada para o preenchimento do leito, conforme mostra a Figura 5. Isto representa um aumento na resistência ao escoamento de ar, e como consequência, faz-se necessário um maior escoamento de ar para manter o leito na condição de mínimo jorro. Assim, maiores valores de velocidade mínima de jorro são obtidos quando a massa de material inerte é aumentada. Resultados semelhantes também foram observados por Rodrigues (1993), Wang et al. (2004), Salam and Bhattacharya (2006) e Qin et al. (2012). 
Figura 5 - Massa de material inerte e suas respectivas alturas de leito estático.

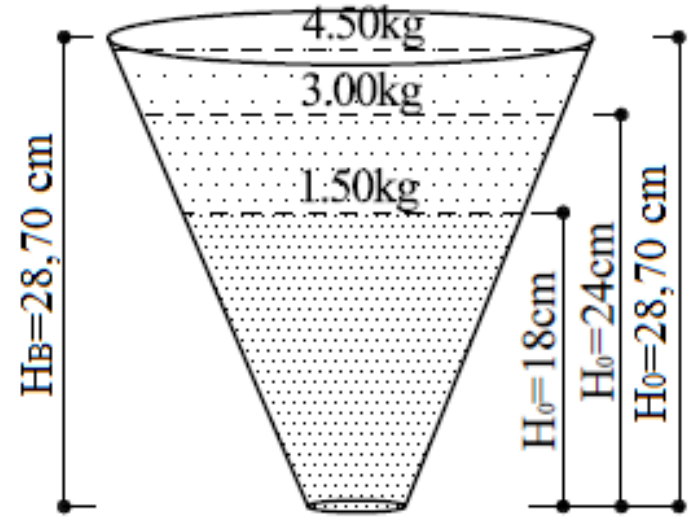

A Figura 6 apresenta os valores médios da queda de pressão máxima do leito em função da massa de material inerte para $o$ bocal do tipo Venturi e temperatura do ar de entrada de $100^{\circ} \mathrm{C}$.

Figura 6 - Valores médios de queda de pressão máxima em função da massa de material inerte.

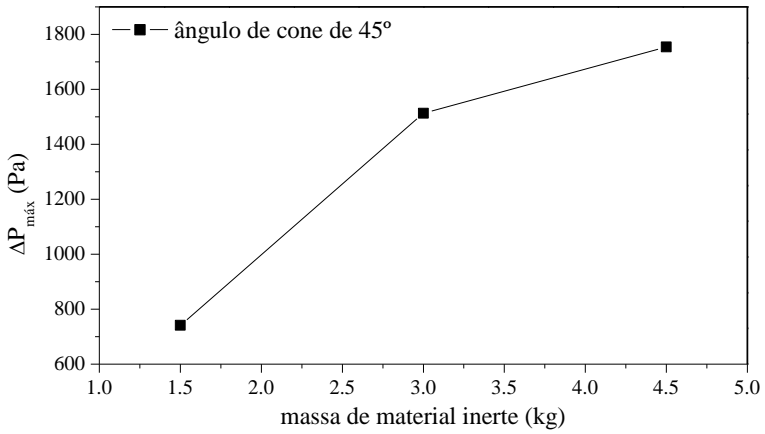

Os dados apresentados na Figura 6 mostraram um aumento mais acentuado dos valores da queda de pressão máxima, $\Delta \mathrm{P}_{\text {máx }}$, com o aumento da massa de material inerte de 1,50 para $3,00 \mathrm{~kg}$. A variação de 3,00 para $4,50 \mathrm{~kg}$ de partículas também elevou os valores de $\Delta \mathrm{P}_{\text {máx }}$, porém um pouco menos expressivo. Isto ocorre porque, apesar da variação da massa de material inerte ser a mesma $(1,50 \mathrm{~kg})$, a diferença da altura de leito estático é maior entre os valores de $m_{p}$ de 1,50 e $3,00 \mathrm{~kg}\left(\Delta \mathrm{H}_{0}=6 \mathrm{~cm}\right)$. Para a mudança de 3,00 para $4,50 \mathrm{~kg}$ de partículas o valor de $\Delta \mathrm{H}_{0}$ é equivalente a $4,70 \mathrm{~cm}$. Esta variação de $\Delta \mathrm{H}_{0}$ está relacionada com as características geométricas da base cônica de $45^{\circ}$. Conforme mostra a Figura 5, esta base cônica é estreita, assim um aumento qualquer da massa eleva o valor de $\Delta \mathrm{H}_{0}$, porém à medida que o diâmetro do cone se aproxima do diâmetro da coluna cilíndrica (neste caso $30 \mathrm{~cm}$ ), a variação de $\mathrm{H}_{0}$ é menor. Estes resultados mostraram que, a quantidade de material inerte exerce efeito nos valores de $\Delta \mathrm{P}_{\text {máx }}$, porém o que determina a intensidade do efeito é a altura do leito estático. Assim, quanto maior o valor de $\Delta \mathrm{H}_{0}$, mais expressivo será o aumento dos valores de $\Delta \mathrm{P}_{\text {máx }}$, uma vez que, será necessária uma maior força para o rompimento do leito de partículas e formação do canal de jorro.

A Figura 7 apresenta os valores médios da queda de pressão de mínimo jorro em função da massa de material inerte para o bocal do tipo Venturi e temperatura do ar de entrada de $100^{\circ} \mathrm{C}$.

Figura 7 - Valores médios de queda de pressão de mínimo jorro em função massa de material inerte.

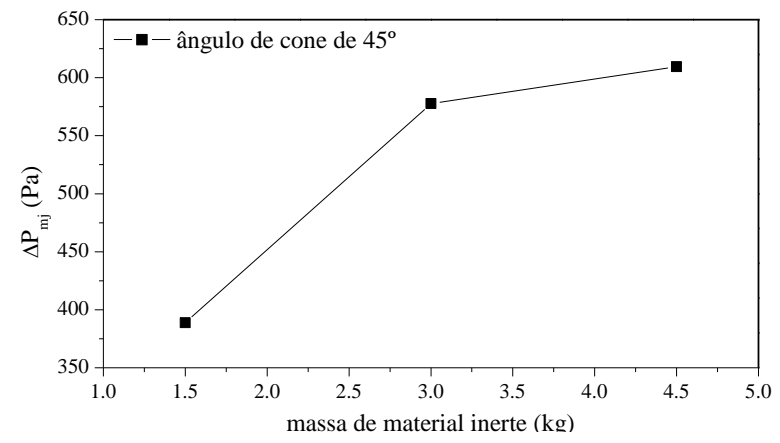

Conforme os resultados apresentados na Figura 7, os valores da queda de pressão de mínimo jorro apresentaram comportamento semelhante aos apresentados anteriormente para a queda de pressão máxima do leito. Desta forma, a mesma explicação é válida para estes resultados.

\subsubsection{Bocal Venturi versus tubo reto}

A Tabela 2 apresenta a comparação entre os valores de velocidade mínima de jorro, queda de pressão máxima e queda de pressão de jorro mínimo obtidos para cada 
geometria de bocal de entrada de ar estudada, a temperatura do ar de entrada de $100^{\circ} \mathrm{C}$.

Tabela 2 - Dados fluidodinâmicos para ambas as geometrias de bocal.

\begin{tabular}{cccc}
\hline Bocal & $\begin{array}{c}\Delta \mathrm{P}_{\text {máx }} \\
(\mathrm{Pa})\end{array}$ & $\begin{array}{c}\Delta \mathrm{P}_{\mathrm{mj}} \\
(\mathrm{Pa})\end{array}$ & $\begin{array}{c}\mathrm{u}_{\mathrm{mj}} \\
(\mathrm{m} / \mathrm{s})\end{array}$ \\
\hline Venturi & 1754,47 & 609,36 & 42,01 \\
Tubo reto & 1377,59 & 424,25 & 42,28 \\
\hline
\end{tabular}

Conforme os dados apresentados na Tabela 2 constataram-se que os valores de queda de pressão máxima e queda da pressão de mínimo jorro foram menores quando utilizados o bocal de entrada de ar tipo tubo reto. Isto porque, a principal função do bocal de entrada de ar é aumentar a velocidade do fluido sem provocar mais turbulência, de modo a diminuir as perdas de carga. $\mathrm{O}$ bocal tubo reto apresenta uma brusca redução da área de escoamento de ar o que provoca turbulência na entrada do leito. No entanto, a vazão de ar que sai do bocal é direcionada totalmente para a região central do leito de partículas (Figura 8a), facilitando o rompimento do canal de jorro. Já o bocal Venturi, promove uma contração e expansão gradual da seção de escoamento de ar. Isto reduz a turbulência na entrada do leito, porém a área de expansão da saída do bocal funciona como um difusor na base do leito e, como consequência, além da direção central, o ar também é direcionado para as laterais da base cônica (Figura 8b). Desta forma, a queda de pressão para o rompimento do leito de partículas é maior quando utilizado o bocal do tipo Venturi. A Figura 8 apresenta um esquema da distribuição de ar na base do leito para ambas as configurações de bocal de entrada de ar.
Figura 8 - Distribuição de ar: (a) tubo reto, (b) Venturi.
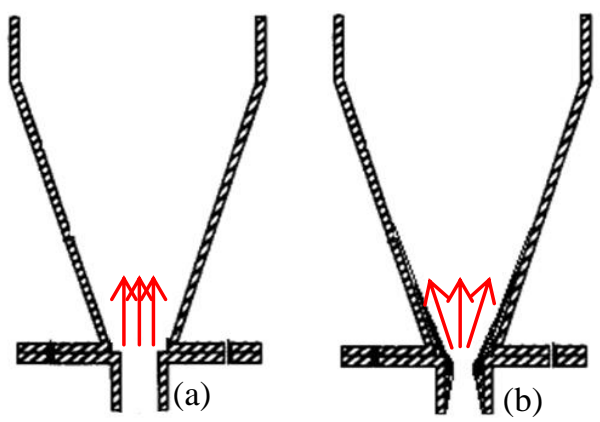

Por outro lado, os valores de $u_{m j}$ para ambos os bocais foram muito próximos. A velocidade mínima de jorro é definida como a velocidade mínima do ar necessária para que o regime de jorro se estabeleça (MATHUR e EPSTEIN, 1974), ou seja, o leito de partículas já foi rompido e houve a formação do canal de jorro. Por isso, a queda de pressão máxima que é definida como a força por unidade de área necessária para o rompimento do leito de partículas e formação do canal de jorro sofre mais efeito da distribuição de ar e demais condições operacionais do que os valores de $u_{m j}$. Os resultados apresentados anteriormente para o efeito da massa de material inerte na fluidodinâmica do leito de jorro (Figuras 4, 6 e 7) já mostraram este comportamento. Os valores de $u_{m j}$ em função da massa de material inerte foram praticamente lineares enquanto que para a queda de pressão máxima comportamento diferenciado foi observado. Outro fator que pode estar contribuindo para estes resultados é a configuração da base cônica utilizada. Bitti (2012) avaliou o efeito da geometria do bocal de entrada de ar empregando os mesmos bocais utilizados neste trabalho. Entretanto, foram usadas esferas de vidro como partículas inertes e ângulo de cone de $60^{\circ}$. O autor também constatou valores mais elevados de queda de pressão máxima quando utilizado o bocal do tipo Venturi. Foi verificado ainda, que para as condições operacionais empregadas os valores de $u_{m j}$ também não sofreram grande influência da geometria do bocal. Entretanto, a diferença 
encontrada foi maior do que a obtida neste trabalho. Isso mostra que, o ângulo de base cônica utilizado interferiu na intensidade do efeito da geometria do bocal de entrada de ar. A distância da parede a posição $\mathrm{r}=0$ é menor para o leito de ângulo $45^{\circ}$ do que para o de $60^{\circ}$. Assim o ar que seria distribuído em direção às laterais (bocal Venturi) fica mais próximo da região central do leito de partículas. Deste modo, os valores de $u_{m j}$ para ambos os bocais são similares quando empregado o ângulo de cone de $45^{\circ}$.

De acordo com Mathur e Epstein (1974), a velocidade mínima de jorro é dependente tanto das propriedades físicas do fluido e das partículas sólidas, quanto das características geométricas do leito. Salam e Bhattacharya (2006) estudaram o efeito da configuração do bocal de entrada de ar no comportamento fluidodinâmico do leito de jorro. Foram estudadas duas configurações distintas, sendo um bocal com fluxo central de ar (Figura 10a) e um bocal com fenda circular (Figura 10b), no qual era variado o diâmetro de entrada de ar. Os resultados mostraram que para uma dada altura de leito estático e área de entrada, a velocidade mínima de jorro foi maior quando utilizado o bocal com fenda circular. Entretanto, á medida que a altura de leito estático e a área de entrada de ar aumentavam, os valores de $u_{m j}$ se aproximavam.

Figura 9 - Bocal de entrada de ar: (a) bocal de jato central e (b) bocal de fenda circular.
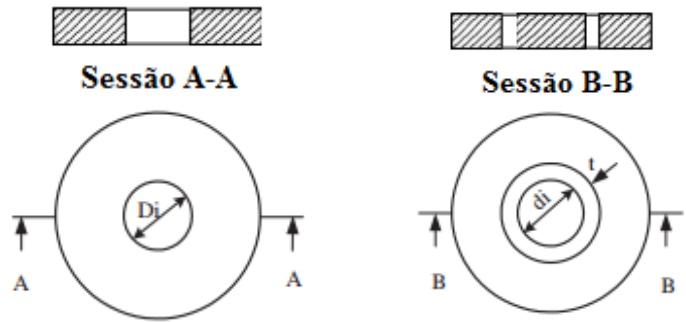

Fonte: Salam e Bhattacharya (2006).

Com base nos resultados obtidos junto à revisão bibliográfica utilizada neste trabalho, constatou-se que as características geométricas do leito exerceram efeito no comportamento fluidodinâmico do leito de jorro. Entretanto, a grandeza do efeito causado por uma determinada variável pode depender das demais condições de operação do processo.

\subsection{Secagem de Leite Desnatado}

Os experimentos de secagem do leite desnatado foram conduzidos para o maior valor de massa de material inerte testado neste trabalho. Visto que, segundo Bitti (2012) e Perazzini, Freire e Freire (2013) a capacidade máxima de evaporação de água do leito elevase quando a massa de material inerte é aumentada. Desta forma, o procedimento experimental foi conduzido empregando-se $4,50 \mathrm{~kg}$ de partículas de polietileno, $100^{\circ} \mathrm{C}$, $1,30 u_{m j}$, ângulo de base cônica de $45^{\circ}$ e duas geometrias de bocal de entrada de ar, conforme já especificadas na Figura 2.

A Figura 10 apresenta o adimensional da queda de pressão do leito de jorro em função do tempo para a secagem de leite desnatado empregando o bocal de entrada de ar do tipo Venturi.

Figura 10 - Adimensional da queda de pressão em função do tempo para o bocal do tipo Venturi a $100^{\circ} \mathrm{C}$ e $1,30 u_{m j}$.

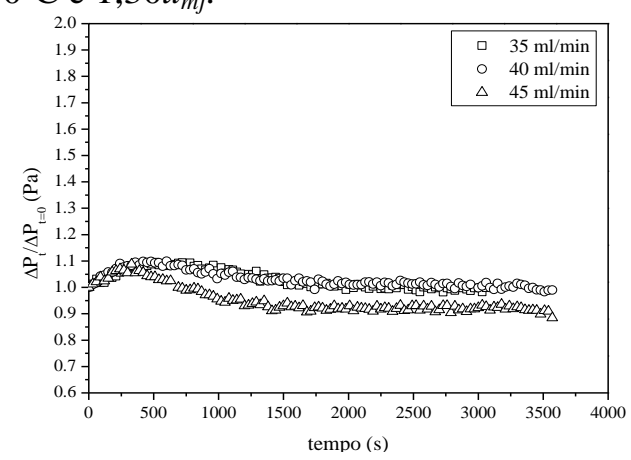

Os resultados apresentados na Figura 10 mostraram nitidamente que para as condições operacionais avaliadas, o adimensional da queda de pressão elevou-se um pouco nos instantes iniciais da secagem do leite 
desnatado, e ao longo do tempo tendeu a ficar constante e igual a 1 , com exceção da vazão de alimentação de $45 \mathrm{~mL} / \mathrm{min}$, vazão na qual o leito entrou em colapso. O comportamento obtido foi muito semelhante ao já apresentado por Almeida (2009), Bitti (2012) e Nascimento (2013) para a evaporação de água. Entretanto, Almeida (2009) e Nascimento (2013) observaram altos valores do adimensional da queda de pressão e dificuldade de movimentação dos inertes durante a secagem de leite desnatado em um leito de jorro com ângulo de cone de $60^{\circ}$. De acordo com Nascimento (2013), este comportamento está diretamente relacionado com a ausência de gordura do leite desnatado e a presença do açúcar que causam dificuldade de circulação dos inertes, acúmulo de pasta na superfície das partículas, e por consequência elevam os valores de $\Delta \mathrm{P}_{\mathrm{t}} / \Delta \mathrm{P}_{\mathrm{t}=0}$. Os resultados obtidos neste trabalho sugerem que esta configuração de leito (ângulo de cone de $45^{\circ}$ e bocal Venturi) não "sentiu" os efeitos da composição da pasta, tendo em vista os baixos valores do adimensional da queda de pressão obtidos durante a secagem de leite desnatado.

O bom desempenho do leito utilizando o ângulo de $45^{\circ}$ se deve ao fato, desta configuração promover maior agitação das partículas inertes. Elperin et al. (1967) citado por Mathur e Epstein (1974) observaram que em leitos cônicos, os ângulos de cone de 40$45^{\circ}$ maximizaram a taxa de circulação dos sólidos no leito. Olazar, San José e Bilbao (2011) relataram que ângulos de cone maiores que $60^{\circ}$ não são recomendados, visto que apresentam taxa de circulação de inertes baixa, principalmente para leitos com grande quantidade de partículas. Desta forma, acredita-se que a maior agitação vinda das partículas inertes seja suficiente para vencer os efeitos negativos causados pela ausência de gordura do leite desnatado, observados por Almeida (2009) e Nascimento (2013).
A Figura 11 apresenta o adimensional da queda de pressão do leito de jorro em função do tempo para a secagem de leite desnatado empregando o bocal de entrada de ar do tipo tubo reto.

Figura 11 - Adimensional da queda de pressão em função do tempo para o bocal do tipo tubo reto a $100 \mathrm{C}$ e $1,3 u_{m j}$.

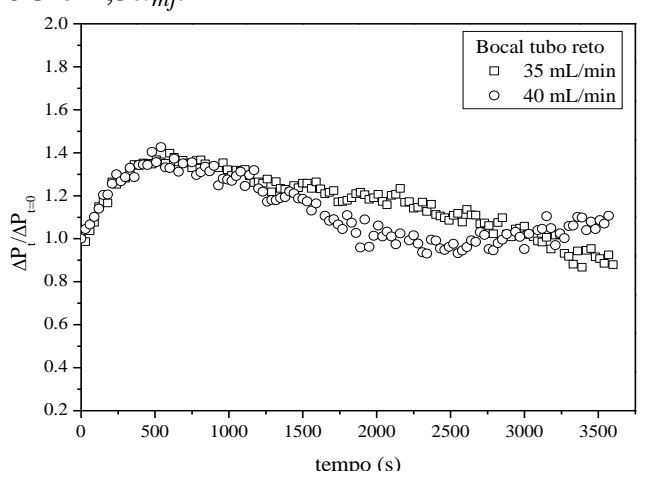

Os resultados apresentados na Figura 11 mostraram que, o adimensional da queda de pressão foi um pouco mais elevado quando empregado o bocal do tipo tubo reto. Este comportamento está relacionado com o fato já discutido anteriormente sobre a distribuição de ar promovida por cada configuração de bocal. Como o bocal Venturi funciona como um difusor de ar na base do leito acredita-se que este auxilie na agitação das partículas inertes. Além disso, conforme mostra a Figura 12a, o bocal Venturi possui uma angulação, o que facilita o movimento dos inertes na base do leito. Já o tubo reto (Figura 12b) possui uma seção reta de $0,40 \mathrm{~cm}$, onde as partículas podem se depositar na base do leito e dificultar o movimento cíclico característicos do regime de jorro.

Os experimentos de secagem mostram ainda que a capacidade de secagem do leito de jorro foi maior quando empregado o bocal do tipo Venturi, no qual a capacidade máxima de secagem para esta configuração foi 40 $\mathrm{mL} / \mathrm{min}$ e $35 \mathrm{~mL} / \mathrm{min}$ para o bocal tubo reto. 
Figura 12 - Configuração do bocal de entrada de ar: (a) Venturi e (b) tubo reto.
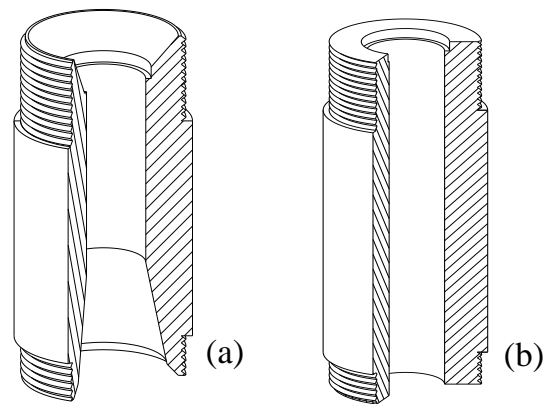

Com base nos resultados apresentados verificou-se que, as características geométricas do leito exerceram efeito tanto no adimensional da queda de pressão quanto na capacidade de secagem do leito. Verificou-se ainda que, houve um efeito conjunto do ângulo de cone e da geometria do bocal de entrada de ar. Isto mostra que, o processo de secagem em leito de jorro é complexo e além das características da pasta, as demais variáveis de processo também devem ser levadas em consideração.

\section{CONCLUSÕES}

Baseado nos resultados obtidos durante a caracterização fluidodinâmica do leito de jorro, concluiu-se que para as condições operacionais avaliadas, houve um aumento dos valores de velocidade mínima de jorro, queda de pressão máxima e queda de pressão de jorro mínimo com o aumento da massa de material inerte. No entanto, verificou-se que a intensidade do efeito causado pela quantidade de inertes é dependente da altura do leito de partículas. Foi possível constatar ainda, que os valores de $\Delta P_{\text {máx }}$ e $\Delta P_{m j}$ foram menores quando utilizado o bocal do tipo tubo reto. Entretanto, para a velocidade mínima de jorro não foi observada grande interferência do bocal.

Os ensaios de secagem mostraram que, a maior estabilidade e capacidade de secagem do leito foram obtidas empregando o bocal do tipo Venturi. Isto mostra a interferência das características geométricas equipamento na secagem de pastas em leito de jorro. Os resultados obtidos neste trabalho serviram como base para mostrar que, existe a necessidade de avaliar o processo de secagem para diferentes condições operacionais e características distintas de leito. Visto que, até o momento, somente as características da pasta eram levadas em consideração.

\section{NOMENCLATURA}

$\mathrm{D}_{0} \quad$ Diâmetro de entrada do

bocal de entrada de ar

$\mathrm{D}_{\mathrm{i}} \quad$ Diâmetro de entrada da base cônica

$\mathrm{H}_{\mathrm{B}} \quad$ Altura da base cônica

P Pressão

$\mathrm{P}_{\text {máx }}$ Pressão máxima do $\left[\mathrm{ML}^{-1} \mathrm{~T}^{-2}\right]$ leito de jorro

$\mathrm{P}_{\mathrm{mj}} \quad$ Pressão na condição de $\left[\mathrm{ML}^{-1} \mathrm{~T}^{-2}\right]$ mínimo jorro

$\mathrm{P}_{\mathrm{t}}$ Pressão do leito de $\left[\mathrm{ML}^{-1} \mathrm{~T}^{-2}\right]$ jorro no tempo

$\mathrm{P}_{\mathrm{t}=0}$ Pressão do leito de $\left[\mathrm{ML}^{-1} \mathrm{~T}^{-2}\right]$ jorro no tempo zero

$\mathrm{R}^{2}$ Coeficiente de [-] determinação

$\mathrm{u}_{\mathrm{mj}} \quad$ Velocidade mínima de $\quad\left[\mathrm{LT}^{-1}\right]$ jorro

$\Delta \quad$ Diferença

\section{REFERÊNCIAS}

ALMEIDA, A, R, F. Análise da secagem de pastas em leito de jorro. 2009. 165 p. Tese (Doutorado em Engenharia Química) Universidade Federal de São Carlos, São Carlos, 2009.

BITTI, M. T. Avaliação das condições operacionais na taxa de evaporação de água em leito de jorro. 2012. 59 p. Dissertação (Mestrado em Engenharia Química) - Universidade Federal de São Carlos, São Carlos, 2012. 
MATHUR, K. B; EPSTEIN, N. Spouted

Beds. New York: Academic Press, 1974.

MEDEIROS, M. F. D. Influência da composição química dos materiais no desempenho do processo de secagem de polpas de frutas em leito de jorro. 2001. 247 p. Tese (Doutorado em Engenharia de Processos) - Universidade Estadual de Campinas, Campinas, 2001.

NASCIMENTO, B. S. Análise do efeito da composição química na secagem de pasta em leito de jorro. 2013. 112 p. Tese (Doutorado em Engenharia Química) Universidade Federal de São Carlos, São Carlos, 2013.

OLAZAR, M. et al. Stable operation conditions for gas-solid contact regimes in conical spouted beds. Industrial and Engineering Chemistry Research. v. 31, p. 1784-1792, 1992.

OLAZAR, M,; SAN JOSÉ, M. J.; BILBAO, J. Conical spouted beds. In: EPSTEIN, N.; GRACE, J. R. Spouted and spout-fluid beds: fundamentals and applications. New York: Cambridge University Press, 2011. p. 82-104.

PASSOS, M. L. et al. Drying of pastes in spouted beds of inert particles: design criteria and modeling. Drying Technology, v. 15, n. 2, p. 605-624, 1997.

PERAZZINI, M. T. B.; FREIRE, F. B.; FREIRE, J. T. Influência do Ângulo da Base Cônica na Taxa de Circulação das Partículas Inertes Durante a Secagem de Pastas em Leito de Jorro. In: Congresso Brasileiro de Sistemas Particulados, 36., Maceió, Anais... Maceió, UFAL, 2013.

PHAN, Q. T. Behaviour of a conical spouted bed dryer for animal blood. The Canadian
Journal of Chemical Engineering. v. 6, p. 426-434, 1983.

QUIN, H. et al. Experimental study on spouted bed hydrodynamics for oil shale semi-coke. Energy Procedia, v. 17, p. 17401746, 2012.

RODRIGUES, C. C. Análise da secagem de suspensões em leito de jorro com partículas inertes. 1993. 116 p. Dissertação (Mestrado em Engenharia Química) - Universidade Federal de São Carlos, São Carlos, 1993.

SALAM, P. A.; BHATTACHARYA, S. C. A comparative hydrodynamic study of two types of spouted bed reactor designs. Chemical Engineering Science, v. 61, p. 1946-1957, 2006.

WANG, Z. et al. Determination of minimum spouting velocities in conical spouted beds. The Canadian of Chemical Engineering, v. 82, p.11-19, 2004.

\section{AGRADECIMENTOS}

Os autores agradecem ao $\mathrm{CNPq}$ pelo apoio financeiro. 